\title{
Evaluation of bioresorbable vascular scaffolds in acute coronary syndrome: A two-center, one-year follow-up analysis
}

\author{
Sylwia Iwańczyk ${ }^{1}$, Jarosław Hiczkiewicz ${ }^{2}$, Aleksander Araszkiewicz ${ }^{1}$, \\ Magdalena Łanocha ${ }^{1}$, Daria Adamczak ${ }^{2}$, Wojciech Faron ${ }^{2}$, Stefan Grajek ${ }^{1}$, Maciej Lesiak ${ }^{1}$ \\ ${ }^{1} 1^{\text {st }}$ Department of Cardiology, University of Medical Sciences, Poznan, Poland \\ ${ }^{2}$ Department of Cardiology, Multidisciplinary District's Hospital, Nowa Sol, University of Zielona Gora, Poland
}

\begin{abstract}
Background: Bioresorbable vascular scaffolds (BVS) have emerged as a new treatment option in cardiovascular medicine. Nonetheless, there is still limited data on the use of these novel devices in patients with acute coronary syndromes (ACS). The purpose of this study was to evaluate the feasibility and efficacy of BVS implantation in patients with ACS.

Methods: The present report is a prospective, two-center registry that involved 165 consecutive patients hospitalized with the diagnosis of ACS and treated with the Absorb BVS (Abbot Vascular, Santa Clara, USA). During 1-year, all patients were monitored for the following endpoints: death, myocardial infarction (MI), scaffold thrombosis (ST), target lesion revascularization (TLR), target vessel revascularization (TVR) and target vessel failure (TVF), defined as cardiac death, target vessel MI, and TVR. Results: A total of 165 patients underwent 179 BVS implantations. 94 patients were diagnosed with unstable angina (UA; 57.6\%), 45 with non-ST-segment elevation myocardial infarction (NSTEMI; 27.3\%) and 26 with ST-segment elevation myocardial infarction (STEMI; 15.7\%). Procedural success was achieved in all patients with thrombolysis in myocardial infarction flow 3. During a follow-up of $14.1 \pm 8.5$ months (median 12.4 months, IQR 8.7 [8.4 to 12.1] months) death occurred in 4 (2.4\%) patients, including 2 (1.3\%) cardiac deaths. There was only 1 case of subacute ST (0.66\%), without late ST. The incidence of MI, TLR, TVR and TVF were: $2.65 \%, 2.65 \%, 7.95 \%, 9.3 \%$, respectively.

Conclusions: The present results suggest that BVS implantation in ACS patients is feasible and safe in highly experienced centers. One-year clinical results are encouraging with a low rate of stent thrombosis. (Cardiol J 2018; 25, 4: 479-486)
\end{abstract}

Key words: acute coronary syndrome, acute myocardial infarction, STEMI, NSTEMI, angiography, coronary, bioresorbable devices/polymers

\section{Introduction}

Currently, percutaneous coronary intervention (PCI) with drug-eluting stent (DES) implantation is recognized as the most effective treatment for the majority of patients with acute coronary syndrome (ACS) [1]. Despite improved long-term results, including death, myocardial infarction (MI), stent thrombosis and repeat revascularization, the placement of metallic stents may be associated with some limitations. Permanent presence of a metallic platform stimulates inflammatory and thrombotic reactions and this, in turn, increases predisposition to the development of coronary neoatherosclerosis and thrombosis $[2,3]$. There is also an increased risk of acute and late stent malapposition due to stent undersizing, caused by vasospasm or thrombus sequestration behind

Address for correspondence: Sylwia Iwańczyk, MD, $1^{\text {st }}$ Department of Cardiology, University of Medical Sciences, ul. Długa 1/2, 61-848 Poznań, Poland, tel: +48 6185492 93, fax: +48 6185490 94, e-mail: syl.iwanczyk@gmail.com 
the struts, especially in patients with thrombotic lesions [4-6]. Additionally, metallic stents exclude the possibility of future surgical revascularization of stented segments and may hinder non-invasive imaging techniques.

Efforts focusing on overcoming the foregoing disadvantages of permanent metallic stents allowed the introduction of the new technology of bioresorbable vascular scaffolds (BVS), which seems to be a huge step forward in cardiovascular medicine [7]. Since the first in-human drug-eluting BVS implantation, which took place in 2006, BVS have been shown to be safe and effective in stable patients with noncomplex lesions [8-11]. Nonetheless, there is still limited data on the use of these novel devices in patients presenting with ACS, the most pro-thrombotic form of atherosclerosis. Potential advantages of BVS implantation may be related to the future vessel lumen enlargement, plaque volume reduction and stabilization, vasomotion restoration as well as elimination of some of the triggers for very late stent thrombosis, such as the presence of non-endothelialized struts $[12,13]$. On the other hand, the increased strut thickness of BVS delays endothelialization and correlates with flow disturbance [14], carrying an additional risk of scaffold thrombosis (ST) [14]. Another potential limitation of scaffolds is the increased risk of strut fracture and disruption due to overexpansion. For this reason, precise pre-dilatation and vessel sizing before BVS implantation and post-dilation following implantation should be performed, which may be hard to achieve in thrombotic lesions $[15,16]$.

The main purpose of this study was to evaluate the feasibility, safety and efficacy of BVS implantation in patients presenting with ACS.

\section{Methods}

The present report is a prospective, twocenter registry involving consecutive patients hospitalized between December 2012 and October 2015 with the diagnosis of ACS treated with the implantation of BVS. Eligible patients had at least one significant coronary artery stenosis, with no restrictions as to the number, severity or lesion location. All patients underwent PCI with implantation of at least one BVS (Absorb, Abbott Vascular, Santa Clara, California). The main exclusion criteria were: the presence of cardiogenic shock, patient life expectancy of less than 1 year, the use of metallic stents during the index procedure and the target vessel reference diameter $<2.3 \mathrm{~mm}$ and
Table 1. Exclusion criteria.

Known intolerance to acetylsalicylic acid, heparin,
PLLA, everolimus, contrast material
Active bleeding or coagulopathy or patients
on chronic anticoagulation therapy
Poor compliance
Cardiogenic shock
Comorbidity with limited expected survival
(<1 year)
Severe tortuous, calcified or angulated coronary
anatomy of the study vessel
Fibrinolysis prior to PCI
PCl - percutaneous coronary intervention; PLLA - poly-L-lactide acid

$>3.7 \mathrm{~mm}$ by visual estimate. Detailed exclusion criteria are presented in Table 1.

The scaffold is composed of semicrystalline poly-L-lactide (PLLA) and coated with an amorphous poly-D, L-lactide (PDLA) polymer eluting everolimus, a potent antiproliferative drug. This fully bioresorbable scaffold is radio-lucent, thus 2 platinum markers are placed at each edge of the device to allow easy visualization on angiography or other imaging modalities [17]. The Absorb BVS is a thick-strut scaffold, with the average strut thickness of 157 microns. Currently three diameters (2.5, 3.0, $3.5 \mathrm{~mm})$, and five lengths $(8,12,18,23$, $28 \mathrm{~mm}$ ) are available. The decision to use BVS was left to the discretion of the operator.

The PCI procedure was performed according to current PCI guidelines. Pre- and postdilatation were at the discretion of the operator. The size of balloon for pre-dilatation was selected according to the reference vessel diameter (1:1). Scaffold sizing was based on the visual vessel evaluation. The implantation of a scaffold was performed with gradual pressure increase by 2 atm every $5 \mathrm{~s}$ without exceeding the rated burst pressure. During post-dilatation non-compliant, high-pressure balloons were used with a diameter sized $0.25-0.5 \mathrm{~mm}$ larger than the scaffold. Each patient naive to antiplatelet therapy, received a loading dose of $300 \mathrm{mg}$ acetylsalicylic acid and $600 \mathrm{mg}$ clopidogrel $(\mathrm{n}=41 ; 24.8 \%)$ before or during PCI, followed by the maintenance daily dose of $75 \mathrm{mg}$ of both medications or prasugrel $60 \mathrm{mg}$ p.o. continued with $10 \mathrm{mg}$ daily dose $(\mathrm{n}=3 ; 1.8 \%)$ or ticagrelor $180 \mathrm{mg}$ loading dose and continued with $2 \times 90 \mathrm{mg}$ daily dose $(\mathrm{n}=121 ; 73.3 \%)$. Duration of dual antiplatelet therapy was recommended for a minimum of 12 months. Due to available data sug- 
gesting that BVS may require prolonged dual antiplatelet therapy (DAPT), to mitigate the risk of late and very late ST, the decision about the continuation of DAPT after 12 months was made individually for the patient depending on the thrombosis risk.

A bolus of unfractionated heparin, $100 \mathrm{U} / \mathrm{kg}$ was administered intravenously during the procedure. The remaining pharmacotherapy was administered according to the contemporary guidelines.

The data related to baseline clinical characteristics, procedural and clinical events were collected on an electronic database. During the follow-up period, clinical data were obtained after 30 days, 6 months, 1 year and every following year by direct contact with patients or telephone interview, additionally, a review of medical reports if patients had been hospitalized.

Patients were monitored for the following endpoints: death, MI, ST, target lesion revascularization (TLR), target vessel revascularization (TVR) and target vessel failure (TVF), defined as cardiac death, target vessel MI, and TVR.

ST-segment elevation MI (STEMI) was defined as electrocardiographic ST elevation concomitant with characteristic symptoms of myocardial ischemia and subsequent release of biomarkers of myocardial necrosis [17]. ST-elevation was defined as new ST-segment elevation at the J point in two or more contiguous leads of $>0.1 \mathrm{mV}$ in all leads other than leads V2-V3. For leads V2-V3 the following cut points apply: $\geq 0.2 \mathrm{mV}$ in men $\geq 40$ years, $\geq 0.25 \mathrm{mV}$ in men $<40$ years, or $\geq 0.15 \mathrm{mV}$ in women. New or presumed new left bundle branch block has been considered as STEMI equivalent. Non-ST-segment elevation MI (NSTEMI) definition involved the presence of angina chest pain, with the marked elevation of biomarkers of myocardial necrosis with no evidence of ST-segment elevation in the electrocardiogram (ECG). Unstable angina was considered to be present in patients with symptoms of myocardial ischemia and no troponin elevation, with or without ECG changes indicative of ischemia (e.g., ST segment depression or transient elevation or new $\mathrm{T}$ wave inversion) [18]. Death was defined as all-cause mortality during the follow-up period. The ST was defined according to the Academic Research Consortium definition $[19,20]$. TLR was defined as target segment reintervention including $5 \mathrm{~mm}$ proximal and distal to the scaffold. Revascularization was considered clinically indicated if symptoms of myocardial ischemia were present, and/or positive stress test, electrocardiographic evidence of ischemia at rest, and/or $>70 \%$ diameter in-lesion stenosis on angiography were observed.

Angiographic success was defined as successful scaffold deployment at the intended site with the residual stenosis of less than $30 \%$ (visual estimation), with thrombolysis in myocardial infarction (TIMI) flow grade 3. Procedure success was defined as angiographic success in the absence of in hospital major adverse cardiac events (MACE).

\section{Statistical analysis}

Continuous variables are presented as mean \pm standard deviation or median (interquartile range [IQR]) and categorical variables are presented as counts and percentages. The Kaplan-Meier method was used to generate cumulative incidence curves for composite endpoint. Analysis was carried out using the Statistica software, version 13 (StatSoft Poland).

\section{Results}

A total of 165 ACS patients were treated with a total of 179 BVS implantation within the study period between October 16, 2012, and October 25, 2015. Of these, 94 patients were diagnosed with unstable angina (57.6\%), 45 with NSTEMI $(27.3 \%)$ and 26 with STEMI (15.7\%). Detailed demographic and clinical patient characteristics are presented in Table 2.

Procedural success was obtained in all patients. In 3 cases coronary dissection occurred and was successfully covered with an additional scaffold. No peri-procedural MACE were reported. Pre- and post-dilatation were performed in $94 \%$ and $81 \%$ of patients, respectively. The angiographic characteristics of the lesions treated and the procedure are reported in Table 3.

Complete follow-up was available in $93 \%$ of patients $(n=151)$, however data concerning death were obtained from province governor's office for all patients. The mean time of observation was $14.1 \pm 8.5$ months (median 12.4 months, IQR 8.7 [8.4 to 12.1 ] months). During this period 4 patients died $(2.42 \%), 2$ of cardiovascular cause. Four patients developed recurrent MI (2.65\%), 2 in hospital (1 with new $\mathrm{Q}$ wave formation), and the other 2 within 6 months (1 STEMI and 1 NSTEMI). In 3 cases MI's were related to the target vessel. The composite rate of TVF was 9.3\%. The rate of TLR and TVR was $2.65 \%(\mathrm{n}=4)$, $7.95 \%(\mathrm{n}=12)$, respectively. ST occurred in $1(0.66 \%)$ patient during hospitalization (definite sub-acute thrombosis). No more ST occurred at follow-up (Table 4). 
Table 2. Baseline characteristics.

\begin{tabular}{lc} 
Age & $59.9 \pm 10.6$ \\
Male & $124(75.1 \%)$ \\
STEMI & $26(15.7 \%)$ \\
NSTEMI & $45(27.3 \%)$ \\
Unstable angina & $95(57.6 \%)$ \\
Cardiovascular history: & \\
Prior MI & $44(26.7 \%)$ \\
Prior PCI & $53(32.1 \%)$ \\
Prior CABG & $8(4.8 \%)$ \\
Stroke & $8(4.8 \%)$ \\
Cardiovascular risk factors: & \\
Hypertension & $138(83.6 \%)$ \\
Diabetes mellitus & $36(21.8 \%)$ \\
IDDM & $11(6.7 \%)$ \\
Hyperlipidemia & $138(83.6 \%)$ \\
Smoking, current & $67(40.6 \%)$ \\
Heart failure & $77(46.7 \%)$ \\
NYHA: & \\
I & $28(16.9 \%)$ \\
II & $31(18.8 \%)$ \\
III & $13(7.9 \%)$ \\
IV & $5(3 \%)$ \\
Peripheral artery disease & $16(9.7 \%)$ \\
LVEF < $50 \%$ & $13(7.9 \%)$ \\
\hline
\end{tabular}

Depicted are counts, number, incidence $(\%)$ or mean \pm standard deviation; CABG - coronary artery bypass grafting; eGFR estimated glomerular filtration rate; IDDM - insulin dependent diabetes mellitus; LVEF — left ventricular ejection fraction; $\mathrm{MI}$ - myocardial infarction; NSTEMI - non-ST-segment elevation myocardial infarction; NYHA - New York Heart Association, $\mathrm{PCl}$ - percutaneous coronary intervention; STEMI - ST-segment elevation myocardial infarction

\section{Discussion}

The results of this study showed a high device and procedural success rate, with a relatively low incidence of peri-procedural complications in ACS patients treated with BVS. Also 1-year results are excellent in this group of patients.

The use of bioresorbable scaffolds in ACS patients carries some risks. Correct vessel and scaffold sizing is very important, due to device expansion limits, but correct assessment of target vessel diameter may be difficult due to spasm or the presence of thrombus [21]. Aggressive lesion preparation increases the rate of successful device delivery and correct expansion, thus pre-dilatation is advisable in all patients [22]. However, in settings of ACS such maneuvers carry additional risk
Table 3. Angiography characteristics.

\begin{tabular}{|c|c|}
\hline Single vessel disease & $85(51.5 \%)$ \\
\hline Multivessel disease & $81(49.1 \%)$ \\
\hline \multicolumn{2}{|l|}{ Target vessel location: } \\
\hline LM & $7(4.2 \%)$ \\
\hline LAD & $81(49.1 \%)$ \\
\hline RCA & $29(17.6 \%)$ \\
\hline LCX & $33(20.0 \%)$ \\
\hline Other & $18(10.9 \%)$ \\
\hline \multicolumn{2}{|l|}{ Lesion type: } \\
\hline B1 & $10(6.1 \%)$ \\
\hline $\mathrm{B} 2$ & $142(86.1 \%)$ \\
\hline $\mathrm{C}$ & $4(2.4 \%)$ \\
\hline Calcification & $9(5.5 \%)$ \\
\hline Bifurcation lesion & $20(12.1 \%)$ \\
\hline Thrombus & $12(7.3 \%)$ \\
\hline Restenosis & $5(3.0 \%)$ \\
\hline RVD [mm] & $2.9 \pm 0.3$ \\
\hline $\mathrm{MLD}[\mathrm{mm}]$ & $0.1 \pm 0.2$ \\
\hline Diameter stenosis [\%] & $88.4 \pm 0.07$ \\
\hline IVUS & $4(2.4 \%)$ \\
\hline OCT & $0(0 \%)$ \\
\hline QCA & $12(7.3 \%)$ \\
\hline Visual estimate & $150(90.9 \%)$ \\
\hline Total number of scaffolds & 179 \\
\hline Mean scaffolds per lesion & 1.1 \\
\hline Mean scaffold length per lesion & $21.0 \pm 7.9$ \\
\hline Mean scaffold diameter per lesion & $3.0 \pm 0.4$ \\
\hline Radial approach & $50(30.3 \%)$ \\
\hline Pre-dilatation & $154(94.0 \%)$ \\
\hline $\begin{array}{l}\text { Mean pre-dilatation balloon } \\
\text { diameter }[\mathrm{mm}]\end{array}$ & $2.7 \pm 0.4$ \\
\hline Max pre-dilatation pressure [atm] & $12.8 \pm 2.0$ \\
\hline Post-dilatation & $133(81 \%)$ \\
\hline $\begin{array}{l}\text { Mean post-dilatation balloon } \\
\text { diameter }\end{array}$ & $2.9 \pm 0.6$ \\
\hline Max post-dilatation pressure [atm] & $18.4 \pm 2.8$ \\
\hline \multicolumn{2}{|l|}{ Pre-procedure TIMI-flow: } \\
\hline $0-1$ & $58(34.9 \%)$ \\
\hline 2 & $50(30.3 \%)$ \\
\hline 3 & $58(34.9 \%)$ \\
\hline \multicolumn{2}{|l|}{ Post-procedure TIMI-flow: } \\
\hline $0-1$ & $0(0 \%)$ \\
\hline 2 & $5(3.0 \%)$ \\
\hline 3 & $160(97.1 \%)$ \\
\hline \multicolumn{2}{|l|}{ In-scaffold (visual estimate): } \\
\hline Mean lumen diameter & $2.8 \pm 0.3$ \\
\hline MLD & $3.0 \pm 0.4$ \\
\hline Diameter stenosis & $0.3 \pm 0.01$ \\
\hline \multicolumn{2}{|l|}{$\begin{array}{l}\text { Complications occurring any time } \\
\text { during the procedure: }\end{array}$} \\
\hline MACE & $0(0 \%)$ \\
\hline Dissection & $3(1.8 \%)$ \\
\hline Spasm & $0(0 \%)$ \\
\hline Distal embolism & $0(0 \%)$ \\
\hline No-reflow & $0(0 \%)$ \\
\hline Angiographic success & $165(100 \%)$ \\
\hline Procedure success & $165(100 \%)$ \\
\hline
\end{tabular}

Depicted are counts, number, incidence (\%) or mean \pm standard deviation; IVUS - intravascular ultrasound; LAD - left anterior descending artery; LCX - left circumflex artery; LM - left main; MACE — major adverse cardiac events; MLD - minimal lumen diameter; OCT — optical coherence tomography; RCA — right coronary artery; RVD - reference vessel diameter; TIMI - thromcoronary artery; RV - reference vessel diameter; TIMI - thro
bolysis in myocardial infarction; QCA - quantitative coronary bolysis in my
angiography 
Table 4. Results.

\begin{tabular}{lcc}
\hline $\mathbf{N}=151$ & FU $<30$ days & Total FU \\
\hline All cause death & $1(0.61 \%)$ & $4(2.42 \%)$ \\
Cardiac death & $1(0.61 \%)$ & $2(1.21 \%)$ \\
Any MI & $2(1.32 \%)$ & $4(2.65 \%)$ \\
Target vessel MI & $2(1.32 \%)$ & $3(1.98 \%)$ \\
Scaffold thrombosis & $1(0.66 \%)$ & $1(0.66 \%)$ \\
Target lesion & $2(1.32 \%)$ & $4(2.65 \%)$ \\
revascularization & $3(1.98 \%)$ & $12(7.95 \%)$ \\
Target vessel & & \\
revascularization & & $14(9.27 \%)$ \\
Target vessel failure & $4(2.65 \%)$ & \\
\hline
\end{tabular}

Depicted are counts, number, incidence (\%); MI - myocardial infarction, $\mathrm{FU}$ - follow-up

of plaque disruption, thrombus mobilization and distal embolism. For this reason, in highly thrombotic lesions, thrombus aspiration prior to balloon inflation seems mandatory [23]. In the present study pre-dilatation was performed in as many as $94 \%$ of patients, including 12 cases with thrombus visible on angiography. In all these cases, manual thrombus aspiration was applied prior to predilatation. The overall procedural success rate was $100 \%$, including all cases with evident thrombus. Additionally, the presence of thrombus increases the risk of acute, as well as late scaffold malapposition. However, in the prospective, multi-centre Prague 19 study, the optical coherence tomography (OCT) analysis revealed only $1.1 \%$ of malapposed struts, much less than the number observed in the Absorb Cohort B study (3.5\%) [24, 25]. Currently, the most reliable method of vessel sizing is OCT, which provides precise vessel and lesion measurements, optimal for sizing and positioning of the scaffold. Moreover, OCT allows for accurate assessment of scaffold apposition after completion of the procedure. However, due to limited availability and costs, OCT is generally underused. When quantitative coronary angiography analysis alone is applied, maximal vasodilatation with intracoronary nitroglycerin injection should be obtained prior to measurement. In this study only visual estimations have been applied, which represents a typical clinical approach in an all-comer population of ACS patients. The present results showed that the procedure of BVS implantation, especially regarding to pre-, post-dilatation and vessel sizing, can be safe and effective when it is performed by very experienced operators.
The rate of post-dilatation in this series was high $(81 \%)$, which corresponds to the current opinion of a majority of operators. Post-dilatation should be performed with short non-compliant balloons, for at least 10-30 s [22].

In randomized trials mid and long-term outcomes of PCI procedures with BVS have been assessed predominantly in patients with stable coronary disease and relatively simple lesions [25-29]. Recently, the preliminary report of prospective has been published, randomized all-comer AIDA trial (Amsterdam Investigator-initiateD Absorb strategy all-comers trial) which evaluated the efficacy and performance of Absorb BVS strategy versus XIENCE family everolimus-eluting metallic coronary stent system in the treatment of coronary lesions. There was no significant difference in the rate of TVF between the scaffold versus stent strategy (2-year cumulative event rates, $11.7 \%$ and $10.7 \%$, respectively; hazard ratio [HR] 1.12; 95\% confidence interval [CI] 0.85-1.48; $\mathrm{p}=0.43)$. However, the bioresorbable scaffold was associated with a higher incidence of device thrombosis (31 patients) than the metallic stent (8 patients) through 2 years of follow-up (2-year cumulative event rates, $3.5 \%$ vs. $0.9 \%$; HR 3.87 ; 95\% CI 1.78-8.42; p < 0.001) [29]. As opposed to randomized trials, registries bring more light to the value of bioresorbable technology in allcomer populations, including patients with ACS. In the GHOST-EU, the largest all-comer registry to date, BVS proved to be effective in a wide range of patients, including 563 patients with ACS. At 6 months the incidence of target lesion failure (TLF, composite of cardiac death, target-vessel MI, or clinically driven TLR) reached $4.4 \%$. The rate of Academic Research Consortium (ARC) definite/probable ST (1.5\% at 30 days and $2.1 \%$ at 6 months) was higher when compared to other BVS and DES studies [30]. It should be noted that this study reflects a very early experience of European operators with bioresorbable technology, with an overall post-dilatation rate below $50 \%$. The results varied widely between centers, mainly due to differences in center experience. The outcomes in highly experienced centers were definitely better. Notably, the use of intravascular imaging tools was relatively rare in the GHOST-EU Registry, which might essentially affect outcomes.

A recent large registry published by Puricel et al. [31], reported data following BVS implantation in 1305 unselected patients, including 653 (50\%) patients presented with ACS (19\% STEMI), 
has shown similar results. The rate of probable and definite ST was $1.8 \%$ at 30 days, $2.3 \%$ at 6 months, and $3.0 \%$ at 12 months. In a multivariable analysis, impaired left ventricular function $(\mathrm{p}=0.019)$ and BVS implantation in ostial lesions $(p=0.049)$ were independently associated with ST. In addition, post-procedural minimal lumen diameter (MLD) and reference vessel diameter were significantly lower in the ST group $(\mathrm{p}<0.001$ for both). Authors reported that post-procedural MLDs below $2.4 \mathrm{~mm}$ (for the $2.5-\mathrm{mm}$ to $3.0-\mathrm{mm}$ BVS) and $2.8 \mathrm{~mm}$ (for the $3.5-\mathrm{mm}$ BVS) were associated with an increased risk of thrombosis. Interestingly, the implementation of a BVS-specific implantation procedure significantly decreased the incidence of 12 -month ST from 3.3\% to $1.0 \%$ ( $\mathrm{p}=$ $=0.035$ ). After propensity score analysis ("early experience” group vs. "BVS-specific protocol” group) this result was maintained $(\mathrm{p}<0.012)$ [31]. ACS patients form a special group, where the main concern is the implantation of thick-strut devices into lesions with high thrombus burden [32]. Diletti et al. [23] presented promising clinical results of BVS implantation in 48 STEMI patients at the 30-day follow-up. The overall MACE rate was only $2.6 \%$, including 1 patient, who developed a non- $\mathrm{Q}$ wave MI related to a non-target-vessel [23]. Similarly, the Prague 19 study has shown high efficacy and safety of BVS implantation in STEMI as compared to a control group treated with metallic stents. Out of 41 patients treated with BVS at 6 months there were only $2(5.0 \%)$ events (1 ST in a patient who stopped taking all the prescribed medications and a small MI due to intra-procedural side branch occlusion), whereas there were $4(7.02 \%)$ events in the control [24]. Another registry reported the use of BVS in real-world setting. In the Polish National Registry, data from 30 interventional centers in Poland were collected. Out of 591 patients 52\% presented with ACS. The results have shown high procedural success and a low complication rate with dissection in $2.9 \%$ of patients, slow-flow in $0.5 \%$, no-reflow in $0.17 \%$, and side branch occlusion in $0.33 \%$ [33]. The POLAR ACS study analyzed 100 patients with ACS treated with BVS implantation. At 1-year, $1 \mathrm{MI}$ caused by ST as well as 1 TLR were observed [34]. For comparison, the outcomes of an all-comers registry have shown the relatively high incidence of definite/probable ST (3.1\% at 12 months, all in the first 6 months) in the setting of ACS (37.6\% of STEMI). The rate of composite endpoint (cardiovascular death, any MI, TLR) reached $13.5 \%$, including $4(3 \%)$ cardiac deaths, $4(3 \%)$ STEMIs, 5 (3.8\%) NSTEMIs, 9 (6.8\%)
TLRs, and was comparable with all-comer DES studies, enrolling ACS patients [35-39]. The majority of events occurred in the first 6 months [40]. Imori et al. [41] have showed that in the setting of ACS patients the rates of MACE (composite of death, myocardial infarction, TLR) (9.3\% vs. $4.7 \%, \mathrm{p}=0.003)$ and stent thrombosis $(2.8 \%$ vs. $0.9 \%, \mathrm{p}=0.01)$ were significantly higher in BVS group compared to EES group. However, the authors noticed that the incidence of MACE in BVS patients with postdilatation was comparable to those observed in EES group (6.0\% vs. $4.7 \%$, $\mathrm{p}=0.23$ ). These differences were mainly driven by lower rate of TLR. ST rate was also decreased, but not significantly $(2.6 \%$ vs. $0.9 \%, \mathrm{p}=0.045)$. In comparison to presented data, these results are promising. ST occurred in only $1(0.66 \%)$ patient, and the composite rates of TVF was $9.3 \%$ at 1-year follow-up. Recent evidence from clinical trials have shown similar outcomes.

The 3-year ABSORB II study has had a critical impact on BVS technology and has undermined its current state of development [28]. The treatment with Absorb was associated with a 2-fold increased risk of device-oriented clinical events, specifically an increased risk of target-vessel MI (7\% vs. $1 \%$; $\mathrm{p}=0.006$ ), as well as increased risk of late ST compared with Xience (Abbott Vascular). The definite ST occurred in 6 patients who received the Absorb compared with no reported cases of definite or probable stent thrombosis for patients who received the Xience stent. Additionally, Absorb did not result in an improvement in vasomotor tone and was associated with an increase in late lumen loss when compared with the Xience everolimuseluting metallic stent. The question is what has beenlearned from this lesson and what direction of development should now be chosen.

Regarding conclusions from the BVS, every new device should undergo monitored introduction and be limited to strictly selected patient groups. The uture direction for research in BVS technology should be focused on several aspects. Reduction of strut thickness and introduction of rounder strut cross-section will reduce the protrusion of the strut and minimize areas of flow disturbance as well as recirculation zones. Moreover, faster bioresorption without inducing an inflammatory vasculitis will result in fast tissue coverage and firm encapsulation of the struts into the vessel wall. As a result, thrombogenicity could be decreased. Research on the second generation of BVS is underway.

The results of the present study demonstrated the procedural feasibility and efficacy as well as 
clinical safety of BVS implantation in patients presenting with ACS. Nonetheless, due to concerns regarding long-term clinical safety all patients after BVS implantation should be closely monitored. Additionally, data from ongoing trials should be made available in the public domain at regular intervals.

\section{Limitations of the study}

The present findings are mostly limited by the observational nature of a prospective, single-arm study. Head-to-head comparison was not performed with the standards of treatment. Additionally, the follow-up period differed between patients with no minimal observation time. The presented clinical outcomes are encouraging, but require longer follow-up.

\section{Conclusions}

The use of BVS in the documented centers were feasible in most patients with ACS. One-year clinical results are encouraging and were comparable to outcomes reported in patients implanted with second-generation DES. Notably, all patients were treated in two highly experienced centers.

Conflict of interest: Aleksander Araszkiewicz, Stefan Grajek, Maciej Lesiak — grants from Abbott Vascular.

\section{References}

1. Stefanini GG, Holmes DR. Drug-eluting coronary-artery stents. N Engl J Med. 2013; 368(3): 254-265, doi: 10.1056/NEJMra1210816, indexed in Pubmed: 23323902.

2. Lüscher TF, Steffel J, Eberli FR, et al. Drug-eluting stent and coronary thrombosis: biological mechanisms and clinical implications. Circulation. 2007; 115(8): 1051-1058, doi: 10.1161/CIRCULATIONAHA.106.675934, indexed in Pubmed: 17325255.

3. Nakazawa G, Otsuka F, Nakano M, et al. The pathology of neoatherosclerosis in human coronary implants bare-metal and drug-eluting stents. J Am Coll Cardiol. 2011; 57(11): 1314-1322, doi: 10.1016/j.jacc.2011.01.011, indexed in Pubmed: 21376502.

4. Spaulding C, Henry P, Teiger E, et al. TYPHOON Investigators. Sirolimus-eluting versus uncoated stents in acute myocardial infarction. N Engl J Med. 2006; 355(11): 1093-1104, doi: 10.1056/ NEJMoa062006, indexed in Pubmed: 16971716.

5. Stone GW, Lansky AJ, Pocock SJ, et al. HORIZONS-AMI Trial Investigators. Paclitaxel-eluting stents versus bare-metal stents in acute myocardial infarction. N Engl J Med. 2009; 360(19): 1946-1959, doi: 10.1056/NEJMoa0810116, indexed in Pubmed: 19420364 .

6. Brar SS, Leon MB, Stone GW, et al. Use of drug-eluting stents in acute myocardial infarction: a systematic review and meta-analysis. J Am Coll Cardiol. 2009; 53(18): 1677-1689, doi: 10.1016/j. jacc.2009.03.013, indexed in Pubmed: 19406344.
7. Serruys PW, Garcia-Garcia HM, Onuma Y. From metallic cages to transient bioresorbable scaffolds: change in paradigm of coronary revascularization in the upcoming decade? Eur Heart J. 2012; 33(1): 16-25, doi: 10.1093/eurheartj/ehr384, indexed in Pubmed: 22041548.

8. Ormiston JA, Serruys PW, Onuma Y, et al. First serial assessment at 6 months and 2 years of the second generation of absorb everolimus-eluting bioresorbable vascular scaffold: a multi-imaging modality study. Circ Cardiovasc Interv. 2012; 5(5): 620-632, doi: 10.1161/CIRCINTERVENTIONS.112.971549, indexed in Pubmed: 23048057.

9. Dudek D, Onuma Y, Ormiston JA, et al. Four-year clinical follow-up of the ABSORB everolimus-eluting bioresorbable vascular scaffold in patients with de novo coronary artery disease: the ABSORB trial. EuroIntervention. 2012; 7(9): 1060-1061, doi: 10.4244/EIJV7I9A168, indexed in Pubmed: 21959320.

10. Serruys PW, Onuma Y, Dudek D, et al. Evaluation of the second generation of a bioresorbable everolimus-eluting vascular scaffold for the treatment of de novo coronary artery stenosis: 12-month clinical and imaging outcomes. J Am Coll Cardiol. 2011; 58(15): 1578-1588, doi: 10.1016/j.jacc.2011.05.050, indexed in Pubmed: 21958884.

11. Onuma Y, Serruys PW, Ormiston JA, et al. Three-year results of clinical follow-up after a bioresorbable everolimus-eluting scaffold in patients with de novo coronary artery disease: the ABSORB trial. EuroIntervention. 2010; 6(4): 447-453, doi: 10.4244/EIJ30V6I4A76, indexed in Pubmed: 20884431.

12. Diletti R, Farooq V, Girasis C, et al. Clinical and intravascular imaging outcomes at 1 and 2 years after implantation of absorb everolimus eluting bioresorbable vascular scaffolds in small vessels. Late lumen enlargement: does bioresorption matter with small vessel size? Insight from the ABSORB cohort B trial. Heart. 2013; 99(2): 98-105, doi: 10.1136/heartjnl-2012-302598, indexed in Pubmed: 23118346.

13. Serruys PW, Onuma Y, Garcia-Garcia HM, et al. Dynamics of vessel wall changes following the implantation of the absorb everolimus-eluting bioresorbable vascular scaffold: a multi-imaging modality study at 6, 12, 24 and 36 months. EuroIntervention. 2014; 9(11): 1271-1284, doi: 10.4244/EIJVI11A217, indexed in Pubmed: 24291783.

14. Kolandaivelu K, Swaminathan R, Gibson WJ, et al. Stent thrombogenicity early in high-risk interventional settings is driven by stent design and deployment and protected by polymer-drug coatings. Circulation. 2011; 123(13): 1400-1409, doi: 10.1161/ CIRCULATIONAHA.110.003210, indexed in Pubmed: 21422389.

15. Pan M, Romero M, Ojeda S, et al. Fracture of bioresorbable vascular scaffold after side-branch balloon dilation in bifurcation coronary narrowings. Am J Cardiol. 2015; 116(7): 1045-1049, doi: 10.1016/j.amjcard.2015.07.015, indexed in Pubmed: 26243578.

16. Lesiak M, Araszkiewicz A. „Leaving nothing behind”: is the bioresorbable vascular scaffold a new hope for patients with coronary artery disease? Post Kardiol Interw. 2014; 10(4): 283-288, doi: 10.5114/pwki.2014.46940, indexed in Pubmed: 25489324.

17. Onuma Y, Serruys PW, Perkins LEL, et al. Intracoronary optical coherence tomography and histology at 1 month and 2,3, and 4 years after implantation of everolimus-eluting bioresorbable vascular scaffolds in a porcine coronary artery model: an attempt to decipher the human optical coherence tomography images in the ABSORB trial. Circulation. 2010; 122(22): 2288-2300, doi: 10.1161/CIRCULATIONAHA.109.921528, indexed in Pubmed: 20975003. 
18. Thygesen K, Alpert JS, Jaffe AS, et al. Third Universal Definition of Myocardial Infarction. Circulation. 2012; 126(16): 2020-2035, doi: 10.1161/cir.0b013e31826e1058.

19. Laskey WK, Yancy CW, Maisel WH. Thrombosis in coronary drug-eluting stents: report from the meeting of the Circulatory System Medical Devices Advisory Panel of the Food and Drug Administration Center for Devices and Radiologic Health, December 7-8, 2006. Circulation. 2007; 115(17): 2352-2357, doi: 10.1161/CIRCULATIONAHA.107.688416, indexed in Pubmed: 17470710.

20. Cutlip DE, Windecker S, Mehran R, et al. Academic Research Consortium. Clinical end points in coronary stent trials: a case for standardized definitions. Circulation. 2007; 115(17): 2344-2351, doi: 10.1161/CIRCULATIONAHA.106.685313, indexed in Pubmed: 17470709.

21. Hong MK, Mintz GS, Lee CW, et al. Late stent malapposition after drug-eluting stent implantation: an intravascular ultrasound analysis with long-term follow-up. Circulation. 2006; 113(3): 414-419, doi: 10.1161/CIRCULATIONAHA.105.563403, indexed in Pubmed: 16432073.

22. Tamburino C, Latib A, van Geuns RJ, et al. Contemporary practice and technical aspects in coronary intervention with bioresorbable scaffolds: a European perspective. EuroIntervention. 2015; 11(1): 45-52, doi: 10.4244/EIJY15M01_05, indexed in Pubmed: 25599676

23. Diletti R, Karanasos A, Muramatsu T, et al. Everolimus-eluting bioresorbable vascular scaffolds for treatment of patients presenting with ST-segment elevation myocardial infarction: BVS STEMI first study. Eur Heart J. 2014; 35(12): 777-786, doi: 10.1093/eurheartj/eht546.

24. Kočka V, Malý M, Toušek P, et al. Bioresorbable vascular scaffolds in acute ST-segment elevation myocardial infarction: a prospective multicentre study ,Prague 19'. Eur Heart J. 2014; 35(12): 787-794, doi: 10.1093/eurheartj/eht545, indexed in Pubmed: 24419808.

25. Serruys PW, Ormiston JA, Onuma Y, et al. A bioabsorbable everolimus-eluting coronary stent system (ABSORB): 2-year outcomes and results from multiple imaging methods. Lancet. 2009; 373(9667): 897-910, doi: 10.1016/S0140-6736(09)60325-1, indexed in Pubmed: 19286089.

26. Onuma Y, Dudek D, Thuesen L, et al. Five-year clinical and functional multislice computed tomography angiographic results after coronary implantation of the fully resorbable polymeric everolimus-eluting scaffold in patients with de novo coronary artery disease: the ABSORB cohort A trial. JACC Cardiovasc Interv. 2013; 6(10): 999-1009, doi: 10.1016/j.jcin.2013.05.017, indexed in Pubmed: 24156961.

27. Serruys PW, Chevalier B, Dudek D, et al. A bioresorbable everolimus-eluting scaffold versus a metallic everolimus-eluting stent for ischaemic heart disease caused by de-novo native coronary artery lesions (ABSORB II): an interim 1-year analysis of clinical and procedural secondary outcomes from a randomised controlled trial. Lancet. 2015; 385(9962): 43-54, doi: 10.1016/ /S0140-6736(14)61455-0, indexed in Pubmed: 25230593.

28. Serruys PW, Chevalier B, Sotomi Y, et al. Comparison of an everolimus-eluting bioresorbable scaffold with an everolimuseluting metallic stent for the treatment of coronary artery stenosis (ABSORB II): a 3 year, randomised, controlled, single-blind, multicentre clinical trial. Lancet. 2016; 388(10059): 2479-2491, doi: 10.1016/S0140-6736(16)32050-5, indexed in Pubmed: 27806897.

29. Wykrzykowska J, Kraak R, Hofma S, et al. Bioresorbable scaffolds versus metallic stents in routine PCI. N Engl J Med. 2017; 376(24): 2319-2328, doi: 10.1056/nejmoa1614954.

30. Capodanno D, Gori T, Nef H, et al. Percutaneous coronary intervention with everolimus-eluting bioresorbable vascular scaffolds in routine clinical practice: early and midterm outcomes from the European multicentre GHOST-EU registry. EuroIntervention. 2015; 10(10): 1144-1153, doi: 10.4244/EIJY14M07_11, indexed in Pubmed: 25042421.

31. Puricel S, Cuculi F, Weissner M, et al. Bioresorbable coronary scaffold thrombosis: multicenter comprehensive analysis of clinical presentation, mechanisms, and predictors. J Am Coll Cardiol. 2016; 67(8): 921-931, doi: 10.1016/j.jacc.2015.12.019, indexed in Pubmed: 26916481.

32. Kolandaivelu K, Swaminathan R, Gibson WJ, et al. Stent thrombogenicity early in high-risk interventional settings is driven by stent design and deployment and protected by polymer-drug coatings. Circulation. 2011; 123(13): 1400-1409, doi: 10.1161/ CIRCULATIONAHA.110.003210, indexed in Pubmed: 21422389.

33. Rzeszutko $€$, Siudak $Z$, Włodarczak A, et al. Use of bioresorbable vascular scaffolds in patients with stable angina and acute coronary syndromes. Polish National Registry. Kardiol Pol. 2014; 72(12): 1394-1399, doi: 10.5603/KP.a2014.0147, indexed in Pubmed: 25001567.

34. Dudek D, Rzeszutko $€$, Zasada W, et al. Bioresorbable vascular scaffolds in patients with acute coronary syndromes: the POLAR ACS study. Pol Arch Med Wewn. 2014; 124(12): 669-677, indexed in Pubmed: 25563622.

35. Räber L, Kelbæk H, Ostojic M, et al. Effect of biolimus-eluting stents with biodegradable polymer vs bare-metal stents on cardiovascular events among patients with acute myocardial infarction: the COMFORTABLE AMI randomized trial. JAMA. 2012; 308(8): 777-787, doi: 10.1001/jama.2012.10065, indexed in Pubmed: 22910755.

36. Kang WC, Ahn T, Lee K, et al. Comparison of zotarolimus-eluting stents versus sirolimus-eluting stents versus paclitaxeleluting stents for primary percutaneous coronary intervention in patients with ST-elevation myocardial infarction: results from the Korean Multicentre Endeavor (KOMER) acute myocardial infarction (AMI) trial. EuroIntervention. 2011; 7(8): 936-943, doi: 10.4244/EIJV7I8A148, indexed in Pubmed: 21959255.

37. Palmerini T, Genereux P, Caixeta A, et al. Prognostic value of the SYNTAX score in patients with acute coronary syndromes undergoing percutaneous coronary intervention: analysis from the ACUITY (Acute Catheterization and Urgent Intervention Triage StrategY) trial. J Am Coll Cardiol. 2011; 57(24): 2389-2397, doi: 10.1016/j.jacc.2011.02.032, indexed in Pubmed: 21658558.

38. Dvir D, Barbash IM, Torguson R, et al. Clinical outcomes after treating acute coronary syndrome patients with a drug-eluting stent: results from REWARDS-EMI (Endeavor for Myocardial Infarction Registry). Cardiovasc Revasc Med. 2013; 14(3): 128-133, doi: 10.1016/j.carrev.2013.01.001, indexed in Pubmed: 23642502.

39. Sabate M, Cequier A, Iñiguez A, et al. Everolimus-eluting stent versus bare-metal stent in ST-segment elevation myocardial infarction (EXAMINATION): 1 year results of a randomised controlled trial. Lancet. 2012; 380(9852): 1482-1490, doi: 10.1016/ s0140-6736(12)61223-9.

40. Gori T, Schulz E, Hink U, et al. Clinical, angiographic, functional, and imaging outcomes 12 months after implantation of drug-eluting bioresorbable vascular scaffolds in acute coronary syndromes. JACC Cardiovasc Interv. 2015; 8(6): 770-777, doi: 10.1016/j.jcin.2014.12.244, indexed in Pubmed: 25999097.

41. Imori Y, D'Ascenzo F, Gori T, et al. Impact of postdilatation on performance of bioresorbable vascular scaffolds in patients with acute coronary syndrome compared with everolimus-eluting stents: A propensity score-matched analysis from a multicenter „real-world” registry. Cardiol J. 2016; 23(4): 374-383, doi: 10.5603/CJ.a2016.0052, indexed in Pubmed: 27515481. 